\title{
Prognostic Significance of Treatment Strategies for the Recurrent Hepatocellular Carcinomas After Radical Resection
}

\author{
RYO SAITO, HIDETAKE AMEMIYA, NAOHIRO HOSOMURA, HIROMICHI KAWAIDA, \\ SUGURU MARUYAMA, HIROKI SHIMIZU, SHINJI FURUYA, HIDENORI AKAIKE, \\ YOSHIHIKO KAWAGUCHI, MAKOTO SUDO, SHINGO INOUE, HIROSHI KONO and DAIDUKE ICHIKAWA
}

First Department of Surgery, Faculty of Medicine, University of Yamanashi, Yamanashi, Japan

\begin{abstract}
Background/Aim: The high rate of recurrence and repetitive features of hepatocellular carcinoma $(\mathrm{HCC})$ require specific treatment strategies. This study aimed to evaluate the long-term outcomes of recurrent HCC focusing on clinicopathological factors. Patients and Methods: A total of 104 patients who were treated with re-hepatectomy, radiofrequency ablation (RFA) or transcatheter arterial chemoembolization for recurrent HCC were analyzed. Postrecurrent prognoses were compared between each treatment group based on the presence of adverse prognostic factors (APFs) identified. Results: In the hepatectomy group, the prognosis of patients with APFs was significantly worse compared to those without APFs. By contrast, the survival rate of patients who underwent RFA was not significantly different from those with and without APFs. Conclusion: Our results demonstrate the heterogeneity that exists in terms of the longterm survival of patients with recurrent HCC. The treatment strategy for recurrent HCC should be based on the assessment of presence of APFs to improve long-term prognosis.
\end{abstract}

The development of hepatocellular carcinoma (HCC) is often associated with a background of chronic inflammation and fibrosis of the liver. The pathophysiological features of carcinogenesis result in a high recurrence rate of HCC after hepatectomy $(1,2)$, and most of these recurrent episodes occur in the liver (3). These characteristics of HCC mean that treatment strategies must be considered for the possibility of recurrence and for minimizing its invasiveness to maintain a liver function reserve. Given the high curability of $\mathrm{HCC}$, such

This article is freely accessible online.

Correspondence to: Daisuke Ichikawa, First Department of Surgery, Faculty of Medicine, University of Yamanashi, 1110 Shimokato, Chuo, Yamanashi, 4093898, Japan. Tel \& Fax: +81 552737390, e-mail: dichikawa@yamanashi.ac.jp

Key Words: Hepatocellular carcinoma, recurrence, hepatectomy. treatment strategies can improve the long-term prognosis of the condition (4). Direct-action antiviral agents have been developed recently; these agents induce a highly sustained virologic response ratio in patients with hepatitis $C$ virus infection $(5,6)$, and contribute to the suppression of hepatitis in many cases. However, many reports have demonstrated that intrahepatic recurrences are still common in patients with a history of both HCV treatment and hepatectomy for primary HCC (7), and the pathophysiological features remain to be elucidated for patients with recurrent HCC.

Various treatments have been developed for HCC, with the selection of appropriate regimens usually based on specific patient factors, such as liver function reserve, and tumor factors, such as tumor diameter and number of intrahepatic tumors $(8,9)$. In the HCC treatment algorithm described in the current Japanese Clinical Practice Guidelines (10), hepatectomy and radiofrequency ablation (RFA) are recognized as two of the most radical treatments (11).

Despite the existence of treatment guidelines, the optimal treatment approach, especially in recurrent cases, and the influence of treatment on the long-term prognosis of patients with intrahepatic recurrences are yet unclear $(12,13)$. Thus, this retrospective study aimed to evaluate the long-term outcomes of recurrent HCC, considering the clinicopathological factors of recurrence to propose appropriate treatment strategies for specific cases of recurrent HCC.

\section{Patients and Methods}

Patients and treatments. Between 2007 and 2014, 180 patients underwent radical resection for primary $\mathrm{HCC}$ at the University of Yamanashi Hospital, Japan. Of these, 109 patients developed only intrahepatic recurrence. Five patients who received supporting care and/or systemic chemotherapy were excluded from the study. Finally, 104 patients receiving treatment with re-hepatectomy, RFA, or transcatheter arterial chemoembolization (TACE) for recurrent HCC were included in this study. Our treatment strategies for patients with intrahepatic recurrence were principally based on the current Japanese Clinical Practice Guidelines. These strategies were: i) hepatectomy or RFA, performed for patients with three or fewer 

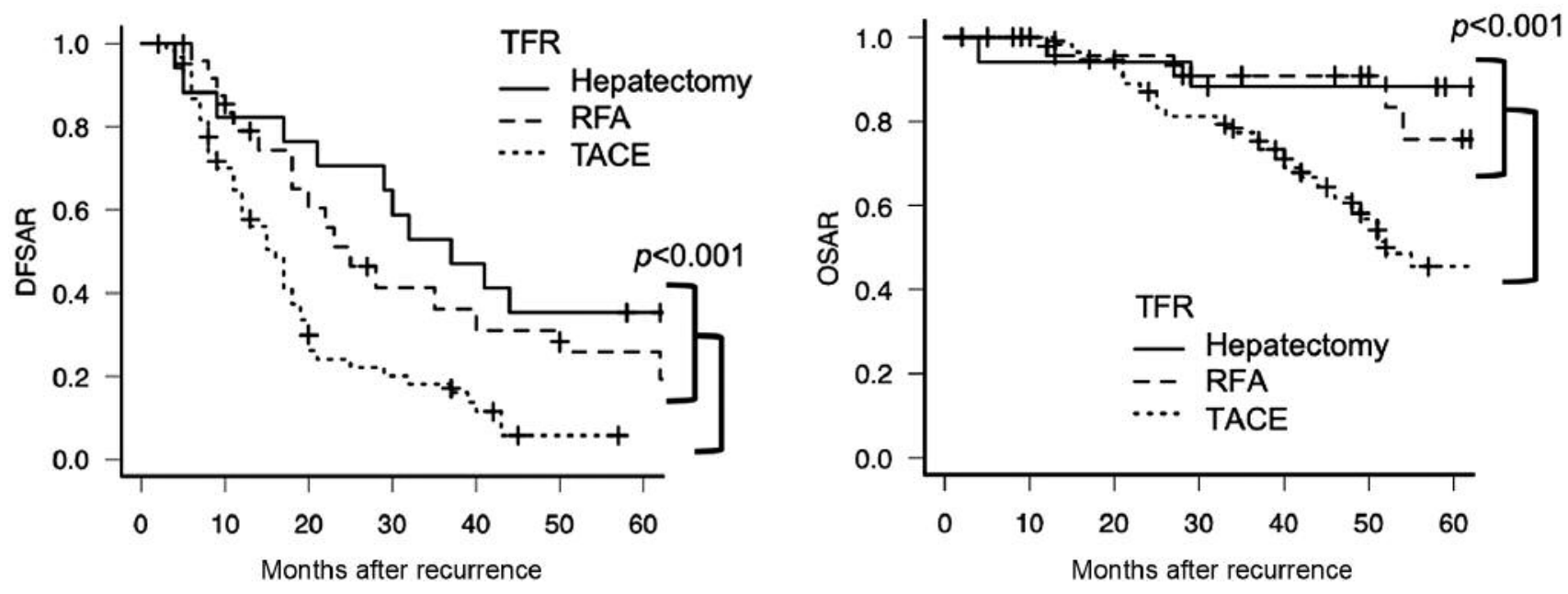

Figure 1. DFSAR and OSAR in each treatment group. The hepatectomy and RFA groups show significantly better prognoses compared to the TACE group in both DFSAR and OSAR ( $<<0.001$, respectively). Significant differences are indicated as $p<0.05$. DFSAR: Disease-free survival after recurrence; OSAR: overall survival after recurrence; RFA: radio frequency ablation; TACE: transcatheter arterial chemoembolization.

intrahepatic recurrent tumors, and ii) TACE, performed in the case of four or more tumors. All study participants provided an informed written consent prior to their study enrollment. This study was approved by the Ethics Committee of the University of Yamanashi (approved number: 2037) and was performed in accordance with the ethical standards of the Declaration of Helsinki and its later amendments (14).

Prognosis after radical hepatectomy for recurrent hepatocellular carcinoma. According to the treatment algorithm, patients with a Child-Pugh classification $\mathrm{C}$ are not suitable for aggressive treatment except for liver transplantation $(15,16)$. Patients with a Child-Pugh classification A or B are equivalently treated, according to the Japanese Clinical Practice Guidelines. In the present study, ChildPugh classification A or B was considered and evaluated as a variable in univariate and multivariate prognostic analyses along with various other clinicopathological factors. The survival rates were compared between each treatment group as values of overall survival after recurrence (OSAR) and disease-free survival after recurrence (DFSAR). Additionally, the potential stratification of patients with intrahepatic recurrence was examined based on the prognostic factors in each treatment group.

Statistical analysis. Five-year survival rates were calculated using the Kaplan-Meier method and analyzed using the log-rank test. Differences were considered statistically significant when $p<0.05$. All statistical analyses were conducted using EZR (Saitama Medical Center, Jichi Medical University, Saitama, Japan), which is a graphical user interface for R (The R Foundation for Statistical Computing, Vienna, Austria) (17).

\section{Results}

Post-recurrent prognosis for each treatment group. Of the 104 patients treated for intrahepatic recurrence in this study,
17, 26, and 61 underwent hepatectomy, RFA, and TACE, respectively. Patients who underwent hepatectomy or RFA had significantly better long-term prognoses in terms of both OSAR and DFSAR, respectively, compared to those who underwent TACE $(p<0.001$ and $p<0.001$, respectively) (Figure 1). This may be attributable to the fact that TACE was principally indicated for patients with a greater number of intrahepatic tumors. However, the prognosis was similar and not significantly different in terms of DFSAR $(p=0.336)$ or OSAR $(p=0.265)$ between patients who underwent hepatectomy and those who underwent RFA.

Prognostic analysis based on adverse prognostic factors. Child-Pugh classification A or B at the time of recurrence was found to be a prognostic factor along with other clinicopathological factors that have been reported in a previous study by our group (18). Multivariate analysis revealed that a Child-Pugh classification $B$ was a significant independent adverse prognostic factor (APF), similarly to early recurrence ( $<1$ year after the primary hepatectomy) and the presence of three or more tumors (Table I). According to the status of APFs in each treatment group, stratified survival analysis clearly demonstrated that the prognosis of patients who underwent hepatectomy was significantly worse in terms of both DFSAR $(p=0.019)$ and OSAR $(p<0.001)$ in those with APFs compared to those without APFs (Figure 2 and Table II). In contrast, the survival rates of patients who underwent RFA did not differ significantly between those with APFs and those without APFs in terms of DFSAR or OSAR ( $p=0.847$ and $p=0.899$, respectively) (Figure 3). 

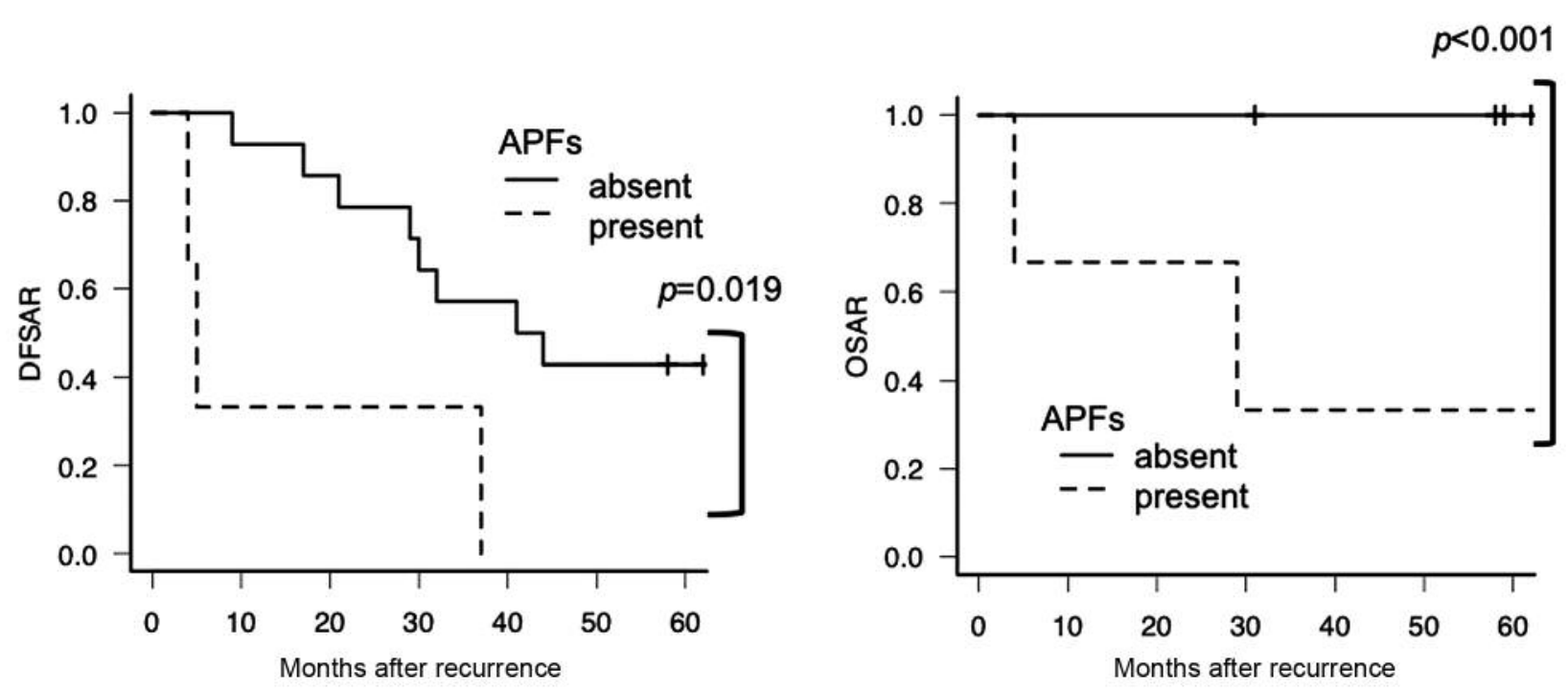

Figure 2. Comparison of post-recurrent prognoses between cases with and without APFs in the hepatectomy group. In the hepatectomy group as recurrence treatment, patients without APFs had significantly better prognoses in both DFSAR and OSAR. Significant differences are indicated as p<0.05. APF: Adverse prognostic factor; DFSAR: disease-free survival after recurrence; OSAR: overall survival after recurrence; RFA: radio frequency ablation; TACE: transcatheter arterial chemoembolization.

\section{Discussion}

The current Japanese Clinical Practice Guidelines (10) apply the same treatment algorithm for both primary and recurrent HCC. However, the clinicopathological features of recurrent $\mathrm{HCC}$ are considerably different from those of primary HCC, as highlighted in our previous report. In addition to the tumor factors, liver function reserve varies, and the classification as Child-Pugh B is more frequently seen in recurrent $\mathrm{HCC}$ compared to primary HCC. Furthermore, the timing of recurrence has not yet been considered as a determining factor in decision making for recurrent HCC treatment.

The long-term results of various treatment strategies for HCC remain controversial, even in the case of primary HCC (19-22). Recently, a multicenter randomized phase IIIcontrolled trial (SURF trial) evaluated the efficacy of surgery versus RFA for primary and small-cell HCC in Japan (23). The results have been analyzed and are yet unpublished, however, an interim report was presented at the 2019 annual meeting of the American Society of Clinical Oncology (24), which revealed that there was no significant difference between hepatectomy and RFA in terms of the 3-year recurrence-free survival, which was one of the primary endpoints. This suggests that RFA is equivalent to hepatectomy in terms of curability and long-term prognosis in some conditions, such as a tumor diameter of $\leq 3 \mathrm{~cm}$, three or fewer tumors, and seven or fewer points on the ChildPugh classification. However, currently, there are no definitive criteria for treatment decisions.
Table I. Post-recurrent prognostic analyses.

\begin{tabular}{|c|c|c|c|c|c|}
\hline \multirow[b]{2}{*}{$\begin{array}{l}\text { Prognostic } \\
\text { factors }\end{array}$} & \multirow[b]{2}{*}{ Factor } & \multirow{2}{*}{$\frac{\text { Univariate }}{p \text {-Value }}$} & \multicolumn{2}{|c|}{ Multivariate } & \multirow[b]{2}{*}{$p$-Value } \\
\hline & & & HR & $95 \% \mathrm{CI}$ & \\
\hline Age & $\geq 70$ & 0.325 & & & \\
\hline Child-Pugh & $\mathrm{B}$ & $<0.001^{*}$ & 2.741 & $1.173-6.406$ & $0.020 *$ \\
\hline AFP (ng/ml) & $\geq 10$ & $0.004 *$ & 1.384 & $0.669-2.864$ & 0.381 \\
\hline $\begin{array}{l}\text { PIVKA-II } \\
(\mathrm{mAU} / \mathrm{ml})\end{array}$ & $\geq 40$ & $0.038^{*}$ & 1.278 & $0.628-2.600$ & 0.499 \\
\hline Tumor size $(\mathrm{mm})$ & $\geq 11$ & 0.416 & & & \\
\hline Tumor number & $\geq 3$ & $<0.001^{*}$ & 2.769 & $1.296-5.919$ & $0.009 *$ \\
\hline $\mathrm{ER} / \mathrm{LR}$ & ER & $<0.001^{*}$ & 2.146 & $1.095-4.207$ & $0.026^{*}$ \\
\hline
\end{tabular}

Significant differences are indicated as $p<0.05^{*}$. HR: Hazard ratio; CI: confidence interval; AFP: $\alpha$-fetoprotein; PIVKA-II: protein induced by vitamin $\mathrm{K}$ absence or antagonist-II; ER: early recurrence; LR: late recurrence.

We hypothesized that hepatectomy and RFA are not equivalent radical treatments and considered that a treatment should be selected on the basis of various factors in each case. In the present study, we identified Child-Pugh classification B, early recurrence of $\mathrm{HCC}$, and the presence of three or more tumors to be APFs for recurrent HCC. Our results demonstrate that there was some heterogeneity in the long-term survival rates of patients treated with recurrent $\mathrm{HCC}$ and there are particular profiles of patient and tumor factors that create either hepatectomy- or RFA-preferable conditions. Specifically, 

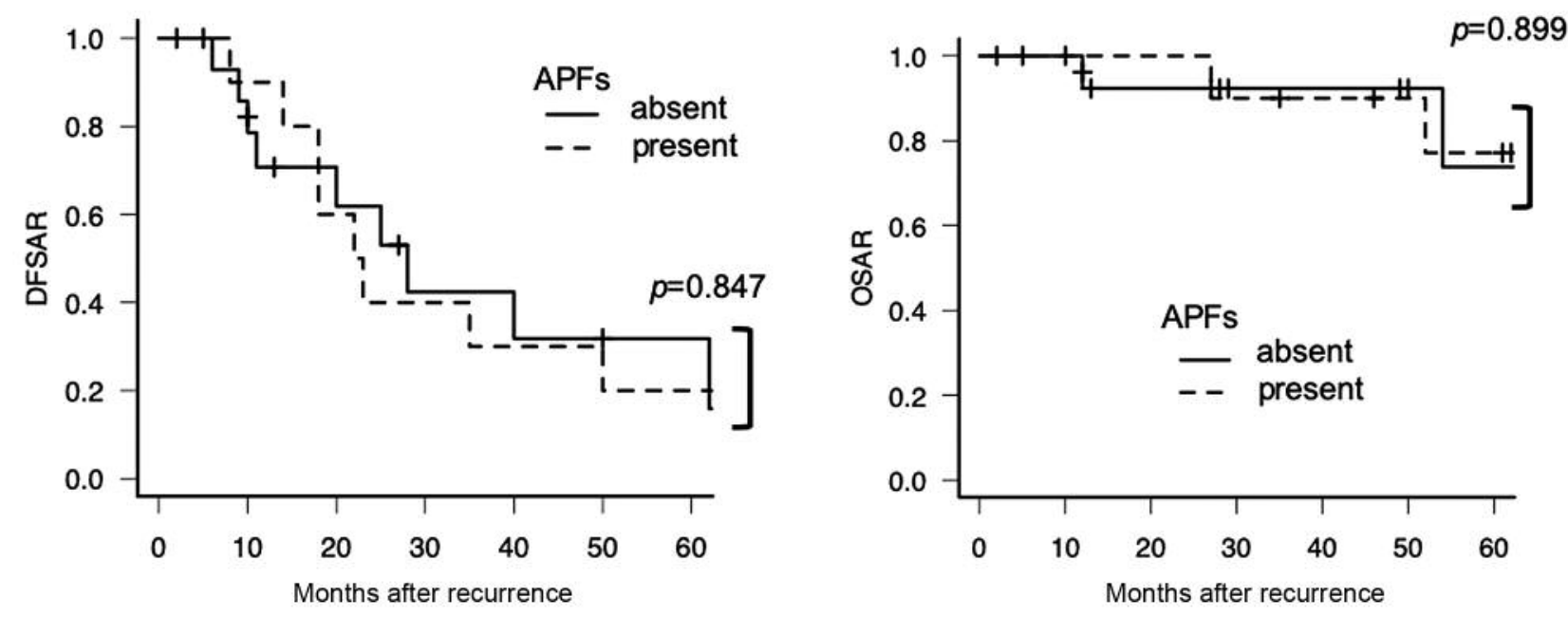

Figure 3. Comparison of post-recurrent prognoses between cases with and without APFs in the RFA group. In the RFA group as recurrence treatment, patients without and without APFs had no significant differences in prognoses in both DFSAR and OSAR. Significant differences are indicated as $p<0.05$. APF: Adverse prognostic factor; DFSAR: disease-free survival after recurrence; OSAR: overall survival after recurrence; RFA: radio frequency ablation; TACE: transcatheter arterial chemoembolization.

Table II. Post-recurrent prognoses based on each treatment and adverse prognostic factors.

\begin{tabular}{|c|c|c|c|c|c|c|c|}
\hline \multirow[b]{2}{*}{ TFR } & \multirow[b]{2}{*}{$\mathrm{n}$} & \multicolumn{3}{|c|}{ DFSAR } & \multicolumn{3}{|c|}{ OSAR } \\
\hline & & 5-YSR & Median & $p$-Value & 5-YSR & Median & $p$-Value \\
\hline \multicolumn{8}{|c|}{ Adverse prognostic factors } \\
\hline \multicolumn{8}{|l|}{ Absent } \\
\hline Hepatectomy & 14 & 0.429 & 42.5 & 0.134 & 1 & NA & $0.043 *$ \\
\hline RFA & 16 & 0.318 & 28 & & 0.738 & NA & \\
\hline TACE & 19 & NA & 20 & & 0.779 & 82 & \\
\hline \multicolumn{8}{|l|}{ Present } \\
\hline Hepatectomy & 3 & NA & 5 & $0.027^{*}$ & 0.333 & 29 & 0.096 \\
\hline RFA & 10 & 0.2 & 22.5 & & 0.771 & NA & \\
\hline TACE & 42 & NA & 13 & & 0.349 & 48 & \\
\hline
\end{tabular}

Significant differences are indicated as $p<0.05^{*}$. DFSAR: Disease-free survival after recurrence; OSAR: overall survival after recurrence; TFR: treatment for recurrence; 5-YSR: 5-year survival rate; RFA: radio frequency ablation; TACE: transcatheter arterial chemoembolization; NA: not available.

recurrent HCC without APFs was associated with a significantly better survival rate compared to recurrent HCC with APFs among patients undergoing hepatectomy. This suggests that hepatectomy should be discouraged in patients presenting with any of the APFs identified in this study. In such cases, RFA would be preferable. Overall, the long-term prognosis of patients with APFs was better in the RFA group, although there were no significant differences between the RFA and hepatectomy groups, due of small sample size $(p=0.201$ for OSAR, Figure 4).

This study has several limitations that should be acknowledged. First, the sample size was small, making it difficult to draw definitive conclusions. Second, due to the retrospective nature of this analysis, the treatment regimens were not always selected according to the treatment algorithm and were instead based on patients' wishes and considerations of medical stuff. Therefore, large-scale prospective studies focusing on the prognostic factors and long-term prognosis following application of the treatment algorithm for recurrent $\mathrm{HCC}$ are necessary to confirm the results of the present study.

In Conclusion, recurrence of $\mathrm{HCC}$ is a common and unavoidable issue in most cases. Therefore, to improve the long-term prognosis of HCC even after its recurrence, it is 


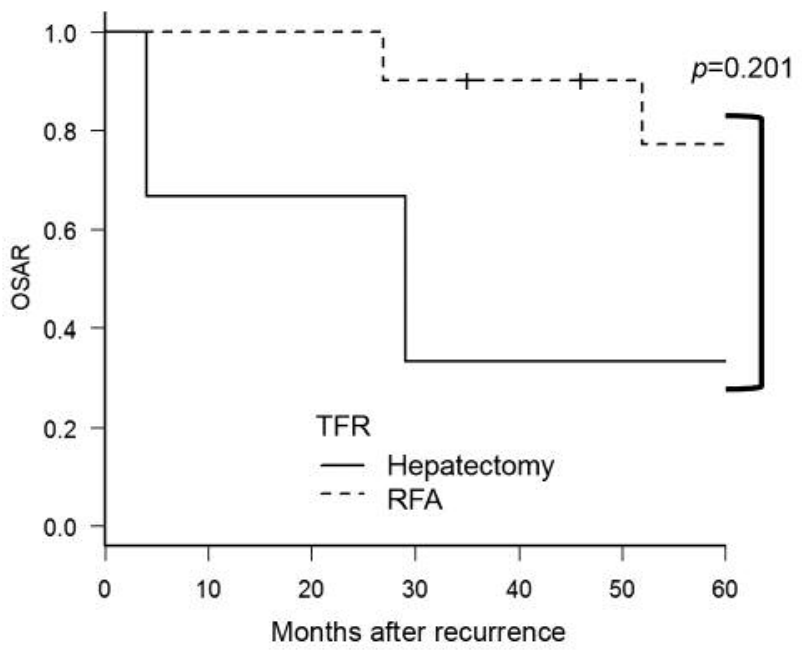

Figure 4. Comparison of OSAR between hepatectomy and RFA group in patients with any of APFs. The long-term prognosis of patients with APFs was better in the RFA group compared to the hepatectomy group although there were no significant differences between the RFA and hepatectomy groups. Significant differences are indicated as $p<0.05$. OSAR: Overall survival after recurrence; RFA: radio frequency ablation.

important to select a treatment strategy that will maintain the liver function reserve, minimize invasive procedures, and optimize the curability. The results of the present study suggest that selecting a treatment strategy for recurrent HCC on the basis of APFs with regards to Child-Pugh classification B, early recurrence of $\mathrm{HCC}$, and the presence of three or more tumors can improve the long-term prognosis for recurrent HCC. This can have considerable benefits for patients with recurrent HCC.

\section{Conflicts of Interest}

None to be declared.

\section{Authors' Contributions}

RS designed the study, and wrote the initial draft of the manuscript. DI and HA contributed to analysis and interpretation of data, and assisted in the preparation of the manuscript. All other Authors have contributed to data collection and interpretation, and critically reviewed the manuscript. All authors approved the final version of the manuscript, and agree to be accountable for all aspects of the work in ensuring that questions related to the accuracy or integrity of any part of the work are appropriately investigated and resolved.

\section{Acknowledgements}

The Authors would like to thank Enago (www.enago.jp) for the English language review.

\section{References}

1 Bruix $\mathbf{J}$ and Llovet JM: Major achievements in hepatocellular carcinoma. Lancet 373(9664): 614-616, 2009. PMID: 19231618. DOI: $10.1016 / \mathrm{s} 0140-6736(09) 60381-0$

2 El-Serag HB: Hepatocellular carcinoma. N Engl J Med 365(12): 1118-1127, 2011. PMID: 21992124. DOI: 10.1056/NEJMra1001683

3 Lacaze L and Scotte M: Surgical treatment of intra hepatic recurrence of hepatocellular carcinoma. World J Hepatol 7(13): 1755-1760, 2015. PMID: 26167248. DOI: 10.4254/wjh.v7.i13.1755

4 Matsuda M, Fujii H, Kono H and Matsumoto Y: Surgical treatment of recurrent hepatocellular carcinoma based on the mode of recurrence: Repeat hepatic resection or ablation are good choices for patients with recurrent multicentric cancer. J Hepatobiliary Pancreat Surg 8(4): 353-359, 2001. PMID: 11521181. DOI: $10.1007 / \mathrm{s} 0053410080353$

5 Mizokami M, Yokosuka O, Takehara T, Sakamoto N, Korenaga M, Mochizuki H, Nakane K, Enomoto H, Ikeda F, Yanase M, Toyoda H, Genda T, Umemura T, Yatsuhashi H, Ide T, Toda N, Nirei K, Ueno Y, Nishigaki Y, Betular J, Gao B, Ishizaki A, Omote M, Mo H, Garrison K, Pang PS, Knox SJ, Symonds WT, McHutchison JG, Izumi $\mathrm{N}$ and Omata M: Ledipasvir and sofosbuvir fixed-dose combination with and without ribavirin for 12 weeks in treatment-naive and previously treated japanese patients with genotype 1 hepatitis c: An open-label, randomised, phase 3 trial. Lancet Infect Dis 15(6): 645-653, 2015. PMID: 25863559. DOI: 10.1016/s1473-3099(15)70099-x

6 Omata M, Nishiguchi S, Ueno Y, Mochizuki H, Izumi N, Ikeda F, Toyoda H, Yokosuka O, Nirei K, Genda T, Umemura T, Takehara T, Sakamoto N, Nishigaki Y, Nakane K, Toda N, Ide T, Yanase M, Hino K, Gao B, Garrison KL, Dvory-Sobol H, Ishizaki A, Omote M, Brainard D, Knox S, Symonds WT, McHutchison JG, Yatsuhashi H and Mizokami M: Sofosbuvir plus ribavirin in japanese patients with chronic genotype $2 \mathrm{hcv}$ infection: An open-label, phase 3 trial. J Viral Hepat 21(11): 762768, 2014. PMID: 25196837. DOI: 10.1111/jvh.12312

7 Roche B, Coilly A, Duclos-Vallee JC and Samuel D: The impact of treatment of hepatitis $\mathrm{c}$ with daas on the occurrence of hcc. Liver Int 38 Suppl 1: 139-145, 2018. PMID: 29427487. DOI: 10.1111/liv.13659

8 Crocetti L, Bargellini I and Cioni R: Loco-regional treatment of hcc: Current status. Clin Radiol 72(8): 626-635, 2017. PMID: 28258743. DOI: $10.1016 /$ j.crad.2017.01.013

9 Yamao T, Imai K, Yamashita YI, Kaida T, Nakagawa S, Mima $\mathrm{K}$, Hashimoto D, Chikamoto A, Ishiko T and Baba H: Surgical treatment strategy for hepatocellular carcinoma in patients with impaired liver function: Hepatic resection or radiofrequency ablation? HPB (Oxford) 20(3): 244-250, 2018. PMID: 28988913. DOI: 10.1016/j.hpb.2017.08.031

10 Kokudo N, Hasegawa K, Akahane M, Igaki H, Izumi N, Ichida T, Uemoto S, Kaneko S, Kawasaki S, Ku Y, Kudo M, Kubo S, Takayama T, Tateishi R, Fukuda T, Matsui O, Matsuyama Y, Murakami T, Arii S, Okazaki M and Makuuchi M: Evidence-based clinical practice guidelines for hepatocellular carcinoma: The japan society of hepatology 2013 update (3rd jsh-hcc guidelines). Hepatol Res 45(2), 2015. PMID: 25625806. DOI: 10.1111/hepr.12464

11 Feng K, Yan J, Li X, Xia F, Ma K, Wang S, Bie P and Dong J: A randomized controlled trial of radiofrequency ablation and surgical resection in the treatment of small hepatocellular carcinoma. J Hepatol 57(4): 794-802, 2012. PMID: 22634125. DOI: $10.1016 /$ j.jhep.2012.05.007 
12 Erridge S, Pucher PH, Markar SR, Malietzis G, Athanasiou T, Darzi A, Sodergren MH and Jiao LR: Meta-analysis of determinants of survival following treatment of recurrent hepatocellular carcinoma. Br J Surg 104(11): 1433-1442, 2017. PMID: 28628947. DOI: 10.1002/bjs.10597

13 Tabrizian P, Jibara G, Shrager B, Schwartz M and Roayaie S: Recurrence of hepatocellular cancer after resection: Patterns, treatments, and prognosis. Ann Surg 261(5): 947-955, 2015. PMID: 25010665. DOI: 10.1097/sla.0000000000000710

14 World medical association declaration of Helsinki: Ethical principles for medical research involving human subjects. JAMA 310(20): 2191-2194, 2013. PMID: 24141714. DOI: 10.1001/ jama.2013.281053

15 Mazzaferro V, Regalia E, Doci R, Andreola S, Pulvirenti A, Bozzetti F, Montalto F, Ammatuna M, Morabito A and Gennari L: Liver transplantation for the treatment of small hepatocellular carcinomas in patients with cirrhosis. N Engl J Med 334(11): 693-699, 1996. PMID: 8594428. DOI: 10.1056/nejm 199603 143341104

16 Todo $\mathrm{S}$ and Furukawa $\mathrm{H}$ : Living donor liver transplantation for adult patients with hepatocellular carcinoma: Experience in japan. Ann Surg 240(3): 451-459; discussion 459-461, 2004. PMID: 15319716. DOI: 10.1097/01.sla.0000137129.98894.42

17 Kanda Y: Investigation of the freely available easy-to-use software 'EZR' for medical statistics. Bone Marrow Transplant 48(3): 452-458, 2013. PMID: 23208313. DOI: 10.1038/bmt. 2012.244

18 Saito R, Amemiya H, Hosomura N, Kawaida H, Maruyama S, Shimizu H, Furuya S, Akaike H, Kawaguchi Y, Sudo M, Inoue $\mathrm{S}$, Kono $\mathrm{H}$ and Ichikawa D: Prognostic factors for post-recurrent survival in hepatocellular carcinoma after curative resection. Anticancer Res 39(6): 3033-3038, 2019. PMID: 31177145. DOI: 10.21873/anticanres. 13436

$19 \mathrm{Xu}$ XL, Liu XD, Liang M and Luo BM: Radiofrequency ablation versus hepatic resection for small hepatocellular carcinoma: Systematic review of randomized controlled trials with meta-analysis and trial sequential analysis. Radiology 287(2): 461-472, 2018. PMID: 29135366. DOI: 10.1148/radiol. 2017162756
$20 \mathrm{Ng} \mathrm{KKC}$, Chok KSH, Chan ACY, Cheung TT, Wong TCL, Fung JYY, Yuen J, Poon RTP, Fan ST and Lo CM: Randomized clinical trial of hepatic resection versus radiofrequency ablation for early-stage hepatocellular carcinoma. Br J Surg 104(13): 1775-1784, 2017. PMID: 29091283. DOI: 10.1002/bjs.10677

21 Yang DJ, Luo KL, Liu H, Cai B, Tao GQ, Su XF, Hou XJ, Ye F, Li XY and Tian ZQ: Meta-analysis of transcatheter arterial chemoembolization plus radiofrequency ablation versus transcatheter arterial chemoembolization alone for hepatocellular carcinoma. Oncotarget 8(2): 2960-2970, 2017. PMID: 27936465. DOI: 10.18632 /oncotarget.13813

22 Hasegawa K, Kokudo N, Makuuchi M, Izumi N, Ichida T, Kudo $\mathrm{M}, \mathrm{Ku} \mathrm{Y}$, Sakamoto M, Nakashima O, Matsui $\mathrm{O}$ and Matsuyama Y: Comparison of resection and ablation for hepatocellular carcinoma: A cohort study based on a japanese nationwide survey. J Hepatol 58(4): 724-729, 2013. PMID: 23178708. DOI: 10.1016/j.jhep.2012.11.009

23 Hasegawa K, Kokudo N, Shiina S, Tateishi R and Makuuchi M: Surgery versus radiofrequency ablation for small hepatocellular carcinoma: Start of a randomized controlled trial (surf trial). Hepatol Res 40(8): 851-852, 2010. PMID: 20649823. DOI: 10.1111/j.1872-034X.2010.00696.x

24 Izumi N, Hasegawa K, Nishioka Y, Takayama T, Yamanaka N, Kudo M, Shimada M, Inomata M, Kaneko S, Baba H, Koike K, Omata M, Makuuchi M, Matsuyama Y and Kokudo N: A multicenter randomized controlled trial to evaluate the efficacy of surgery $v s$. radiofrequency ablation for small hepatocellular carcinoma (SURF trial). J Clin Oncol 37(15): 4002, 2019. DOI: 10.1200/JCO.2019.37.15_suppl.4002

Received December 11, 2019

Revised January 21, 2020

Accepted January 24, 2020 